\title{
STUDY ON ARRANGEMENT OF COOLING WATER PIPE TO CONTROL HYDRATION HEAT OF CONCRETE IN BEAM OF CABLE-STAYED BRIDGE
}

\author{
Long Liu, Saisai Yu, Wentao Xu and Zhilong Wang
}

Anyang Institute of Technology, the west end of Huanghe Avenue, Anyang 455000, China;20160913@ayit.edu.cn

\begin{abstract}
The box girder joint section of the Yangtze River Highway Bridge is taken as the research background, and the finite element software MIDAS/FEA is used to simulate the hydration heat of concrete to the layout of cooling water pipe in building mass concrete. The correlation between the finite element calculation results and the measured data is more than 0.976, which is in good agreement. On this basis, the influence of changing the diameter and distance of the cooling water pipe, the inlet temperature and the flow rate on the temperature of hydration heat is studied. The results show diameter of the cooling water pipe and inlet temperature have a significant effect on the temperature of hydration heat. The change of water flow rate has little effect on the temperature of hydration heat. It provides a reference for the layout of the same concrete cooling water pipe arrangement.
\end{abstract}

\section{KEYWORDS}

Cooling water pipe, Water temperature, Hydration heat, Test, Simulation analysis

\section{INTRODUCTION}

Concrete is a building material mainly composed of cement and aggregate. In the pouring of mass concrete, the internal temperature is much higher than the external temperature, and improper treatment after pouring will produce cracks in the later curing and affect the performance [1-3]. The commonly used measure to reduce the temperature difference between inside and outside the project is to arrange cooling water pipes. Academician Zhu Bofang [4] studied the simplified calculation of polyethylene water pipes in dam cooling. Ding Baoying [5] studied the relationship between concrete and water pipe temperature difference by combining finite element and break mechanics theory. Liu Yaodong [6] studied the influence of different cooling water temperature, flow rate and water pipe spacing on the cooling and crack prevention of the cap, taking the concrete construction of the Yellow River highway and railway bridge in Zhengzhou as the background. Guo Sanyuan [7] determined the appropriate parameters such as the distance, flow rate and cooling water pipes for the bridge through finite element analysis of hydration heat of concrete in the cap of a continuous rigid frame bridge. Taking Chongqing Zhaiziping Bridge as the engineering background, Tang Yang [8] studied the influence of cooling water pipe arrangement, water inlet and temperature on the hydration heat of the cap.

Because of the large volume and serious hydration heat of dam, raft foundation, bridge pier, cap and other parts, more scholars have studied these structures. Liu Guangyan [9] put forward the late heat release model of fly ash with double $\mathrm{E}$ curve, which provides guidance for the late pouring of the dam, through monitoring the Shimao Project (under construction). Chen Zhijun [10] used ANSYS software to simulate the temperature effect of hydration heat in the construction of $178 \mathrm{~m}$ tall blocks and gained the hydration heat effect different from the ordinary mass concrete, which 


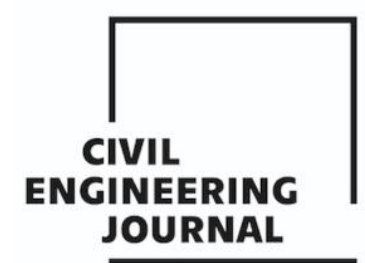

Article no. 39

THE CIVIL ENGINEERING JOURNAL 2-2021

provided reference for designers and builders. Zhang Yongjian [11] used the finite element software MIDAS/CIVIL to simulate the temperature and stress of three auxiliary hole caps of Dongting Lake Bridge with different cement types. The measured results were in well agreement with the calculated results, and the temperature appreciation and average temperature rise rate during the hydration of low-heat cement were significantly reduced. Wang Jianqun [12] settled a rigid frame beam part model by using finite element software, studied the law of temperature field and stress field of hydration heat of concrete in beam part, and determined the reasonable demolish time of concrete.

Therefore, this paper takes the concrete pouring construction recording of a Yangtze River highway bridge as the background and uses the finite element software MIDAS/FEA to settle a threedimensional simulation model to analyze the temperature field variation of concrete hydration heat. Through studying the influence of changing the cooling water pipe and the related parameters of cooling water on the hydration heat, the most suitable diameter and distance of cooling water pipe during concrete pouring and the factors that have great influence on the hydration heat are gained. The correctness of the model is verified by comparing with the measured data, which provides a reference for the ideal layout of cooling water pipes in the control of hydration heat of the same concrete.

\section{BASIC PRINCIPLE}

\section{(1) Transient heat conduction equation}

The essence of calculation of temperature field inside concrete is the solution of heat conduction equation under specific boundary conditions and initial conditions. The three-dimensional transient heat conduction equation is shown in formula (1) and formula (2) [13-14]:

$$
\begin{gathered}
\frac{\partial T}{\partial \tau}=\alpha\left(\frac{\partial^{2} T}{\partial x^{2}}+\frac{\partial^{2} T}{\partial y^{2}}+\frac{\partial^{2} T}{\partial t^{2}}\right)+\frac{\partial \theta}{\partial t} \\
\alpha=\frac{\lambda}{c \rho}
\end{gathered}
$$

Where, $\alpha$ is the thermal conductivity $\left(\mathrm{m}^{2} / \mathrm{h}\right), \lambda$ is the thermal conductivity $(\mathrm{W} /(\mathrm{m} \cdot \mathrm{K})), c$ is the specific heat capacity of the material $\left(\mathrm{J} /\left(\mathrm{kg} \cdot{ }^{\circ} \mathrm{C}\right)\right), \rho$ is the material density $\left(\mathrm{kg} \cdot \mathrm{m}^{3}\right), \theta$ is the adiabatic temperature rise of concrete $\left({ }^{\circ} \mathrm{C}\right), T$ is the time $(\mathrm{h})$.

\section{(2) Initial conditions and boundary conditions}

The heat conduction equation shows the relationship between temperature of an object and time, space, but there are many kinds of situations satisfying the solution of the equation. To determine the unique temperature field, the initial conditions and boundary conditions must be determined.

The initial conditions can be divided into two categories: first, the temperature field is a known function of coordinates; second, the initial temperature distribution is constant. The research content of this paper belongs to the second initial conditions, as shown in formula 3 :

$$
T(x, y, z, 0)=T_{0}(x, y, z)=\text { const }
$$

The boundary conditions can be divided into three categories: first, the boundary temperature of the object is a known temperature; second, the surface heat rate is a known of time; third, when the surface of an object is in contact with air, the rate of heat on the surface of the object is proportional to the temperature. The content of this paper belongs to the third boundary conditions, as shown in formula 4 :

$$
-\lambda \frac{\partial T}{\partial n}=\beta\left(T-T_{a}\right)
$$




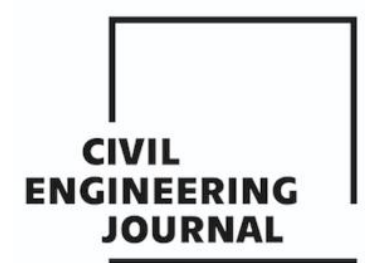

Article no. 39

THE CIVIL ENGINEERING JOURNAL 2-2021

Where, $\beta$ is the surface heat release coefficient $\left(\mathrm{kJ} /\left(\mathrm{m}^{2} \cdot \mathrm{h} \cdot{ }^{\circ} \mathrm{C}\right)\right)$, and $T_{a}$ is the ambient temperature $\left({ }^{\circ} \mathrm{C}\right)$.

\section{(3) Heat source function}

Heat source function is to simulate the process of adiabatic temperature rise in the process of concrete hydration, and its common expressions include exponent, hyperbolic, and so on. The exponential formula is used in this paper, as shown in formula 5:

$$
\theta(t)=\theta_{0}\left(1-e^{m t}\right)
$$

Where, $\theta_{0}$ is the maximum value of concrete adiabatic temperature rise $\left({ }^{\circ} \mathrm{C}\right), \mathrm{m}$ is a constant which is related to cement varieties, casting temperature, and so on.

\section{BACKGROUND}

The main bridge of a Yangtze River Highway Bridge adopts the form of mixed beam, the span composition is $(70+75+84+818+233.5+124.5) \mathrm{m}$. The layout of the bridge facade is shown in Figure1. In this paper, the concrete in the joint section of the mixed beam is taken as the research object. The width of the box girder at this position is $38.90 \mathrm{~m}$, the height of the girder at the center is $3.60 \mathrm{~m}$, and the height of the side and side girders is $(1.981+1.25) \mathrm{m}$. The height of the access hole is $1.60 \mathrm{~m}$, the radius of the chamfered arc is $R=0.40 \mathrm{~m}$, the diameter of the set in steel pipe is $0.80 \mathrm{~m}$, and it is $1.25 \mathrm{~m}$ away from the top surface of the box girder and $0.75 \mathrm{~m}$ away from the bottom of the box girder.

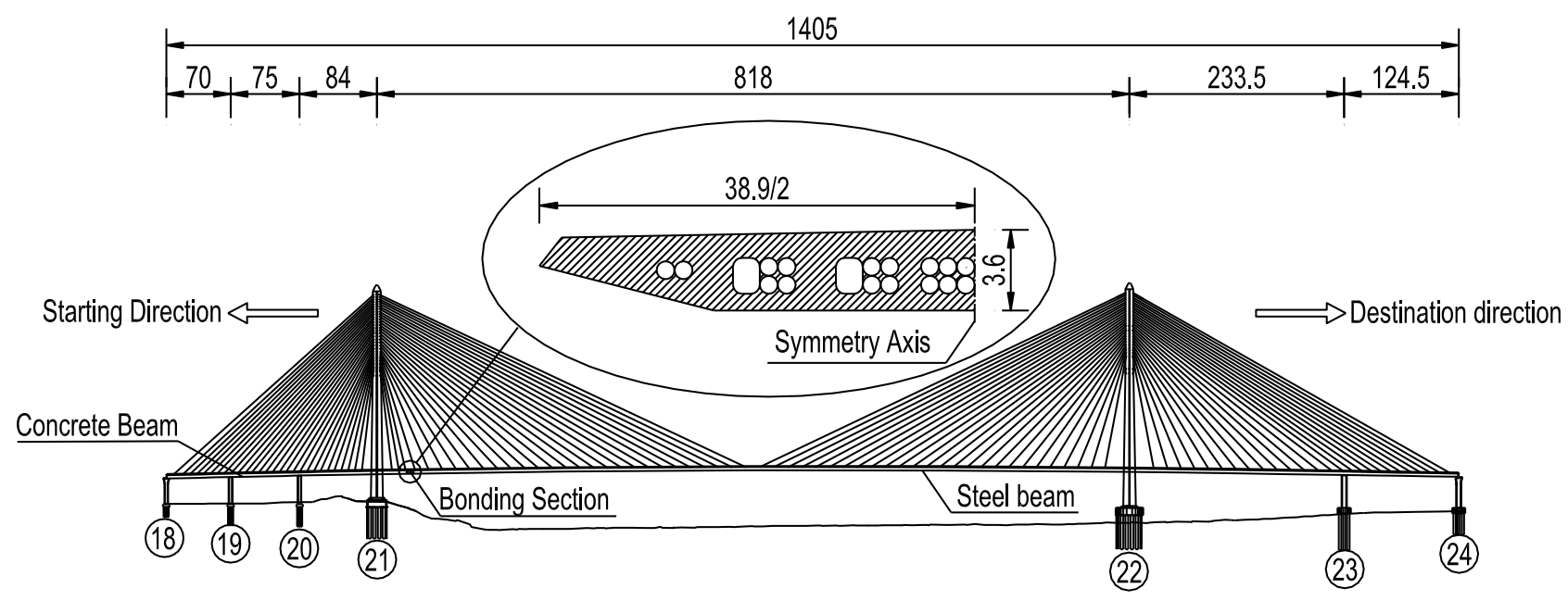

Fig. 1 - Bridge Layout (unit: $m$ )

The concrete box girder adopts horizontal layering method combined with indirect advancing method, and the layering thickness is about $40 \sim 50 \mathrm{~cm}$. The order of casting is bottom plate, web and roof. The concrete fit of the project is shown in Table 1. The physical and thermal parameters of the concrete are shown in Table 2. To reduce the influence of hydration heat, the cooling water pipe is arranged to cool the temperature. The cooling water pipe is arranged in three layers from bottom to top. The distance between the first layer and the second layer is $100 \mathrm{~cm}$, and the distance between the second layer and the bottom layer is $120 \mathrm{~cm}$. The water inlet is arranged on the riverside, and the water outlet is arranged on the bankside. The temperature test points of box girder and the layout of cooling water pipes are shown in Figure2. The measuring range of JMT-36C type resistance sensor is $-20^{\circ} \mathrm{C}$ to $120^{\circ} \mathrm{C}$, and the sensitivity is $0.1^{\circ} \mathrm{C}$. It has the advantages of high precision, strong stability, and insulation, and can cope with long-term temperature recording and automatic recording 
Article no. 39

CIVIL

ENGINEERING

JOURNAL

THE CIVIL ENGINEERING JOURNAL 2-2021

on various occasions. The measured data is the resistance value, and the transformation between temperature and resistance is shown in formula 6:

$$
T=\frac{1}{\left(0.003132398+0.003155718 \times \ln R_{t}+0.0000048255 \times \ln ^{2} R_{t}\right)-273.2}
$$

Where $T$ (unit: ${ }^{\circ} \mathrm{C}$ ) is the temperature value and $R_{T}$ (unit: $\Omega$ ) is the measured resistance value.

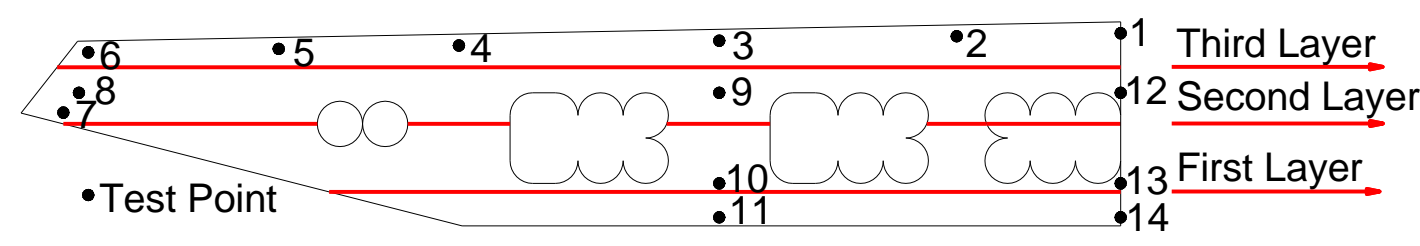
5 E?

(a) Elevation

(b) Plan

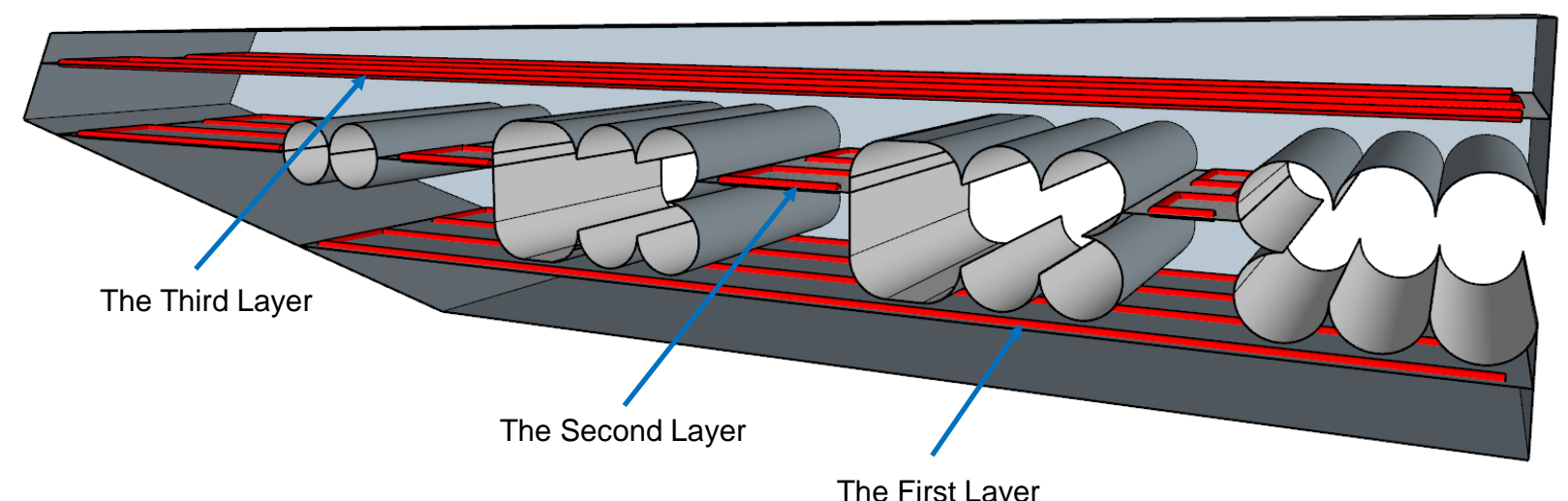

(c) Schematic diagram of cooling water pipe layout

Fig. 2 - Schematic diagram of arranging cooling water pipes and temperature test points in 1/2 beam section

Tab. 1 - Concrete batching table (unit: $\mathrm{kg} / \mathrm{m}^{3}$ )

\begin{tabular}{ccccccc}
\hline Cement & $\begin{array}{c}\text { Gravel }(4.75- \\
9.5 \mathrm{~mm})\end{array}$ & $\begin{array}{c}\text { Gravel (9.5- } \\
19 \mathrm{~mm})\end{array}$ & Sand & Fly ash & $\begin{array}{c}\text { Water } \\
\text { reducing } \\
\text { agent }\end{array}$ & Water \\
\hline 372 & 337 & 792 & 724 & 125 & 5.97 & 150 \\
\hline
\end{tabular}

Tab. 2 - Thermal parameters of concrete

\begin{tabular}{cccccc}
\hline $\begin{array}{c}\text { Strength } \\
(\mathrm{MPa})\end{array}$ & $\begin{array}{c}\text { Poisson's } \\
\text { ratio }\end{array}$ & $\begin{array}{c}\text { Coefficient of } \\
\text { linear } \\
\text { expansion } \\
\left(1 /{ }^{\circ} \mathrm{C}\right)\end{array}$ & $\begin{array}{c}\text { Bulk density } \\
\left(\mathrm{kN} / \mathrm{m}^{3}\right)\end{array}$ & $\begin{array}{c}\text { Specific heat } \\
\text { capacity } \\
\mathrm{kJ} /(\mathrm{kN} \cdot \mathrm{T})\end{array}$ & $\begin{array}{c}\text { Thermal } \\
\text { conductivity } \\
\mathrm{kJ} /(\mathrm{m} \cdot \mathrm{h} \cdot \mathrm{T})\end{array}$ \\
\hline 55 & 0.2 & $1.00 \mathrm{E}-05$ & 25 & 62.9 & 10 \\
\hline
\end{tabular}




\section{FINITE ELEMENT MODEL}

Finite element analysis software MIDAS/FEA is used to settle the three-dimensional model and calculation, because the box girder section and boundary conditions are symmetric, so half of the model is settled. The model has 12,650 nodes and 30,363 elements. The concrete is simulated by hexahedral and wedge elements. The finite element model is shown in Figure 3.

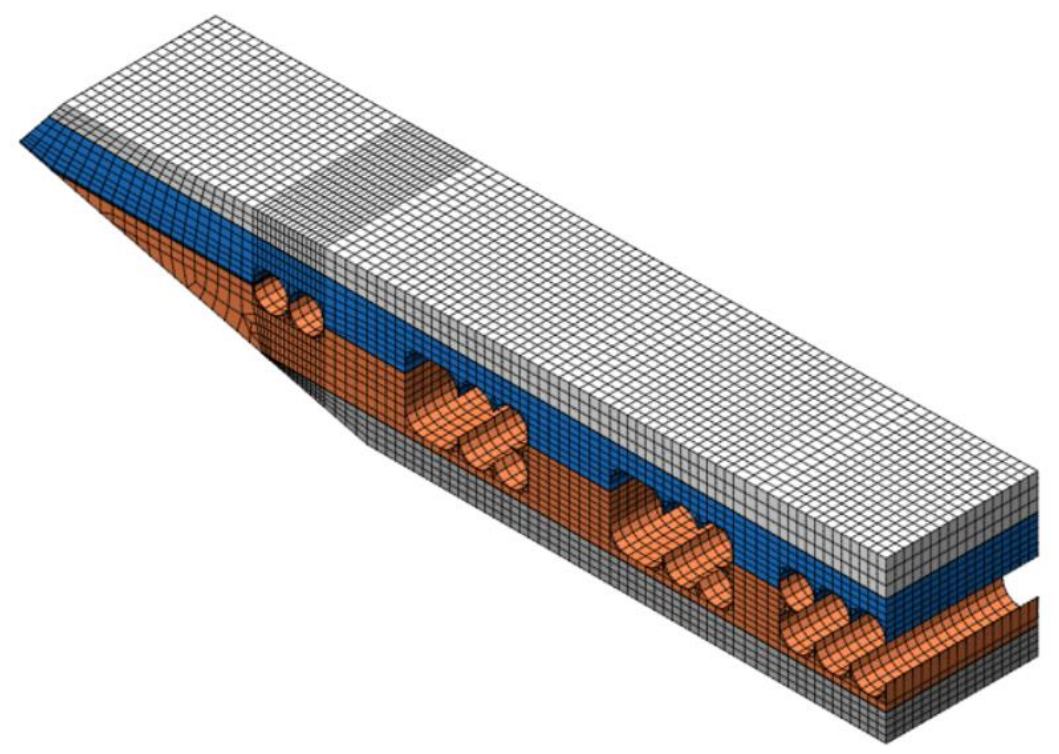

Fig. 3 - Finite element model diagram of box girder

To verify the accuracy of finite element software MIDAS/FEA in the simulation of hydration heat, the calculated values of the model at test point 1 at the top of the roof, test point 3 at the top of the roof and test point 8 at the center of the air nozzle are compared with the measured data, and the results are shown in Figure 4. Figure5 shows the temperature cloud map of finite element calculation at $35 \mathrm{~h}$.

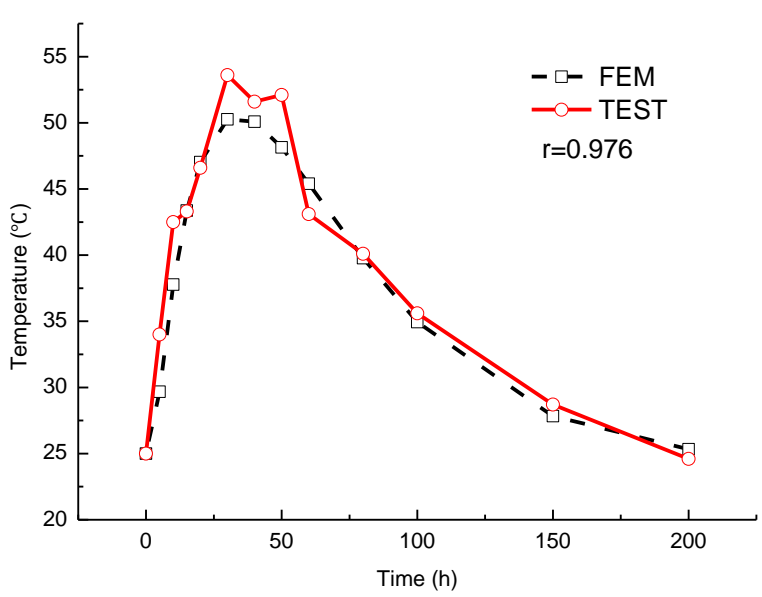

(a) Test point 1

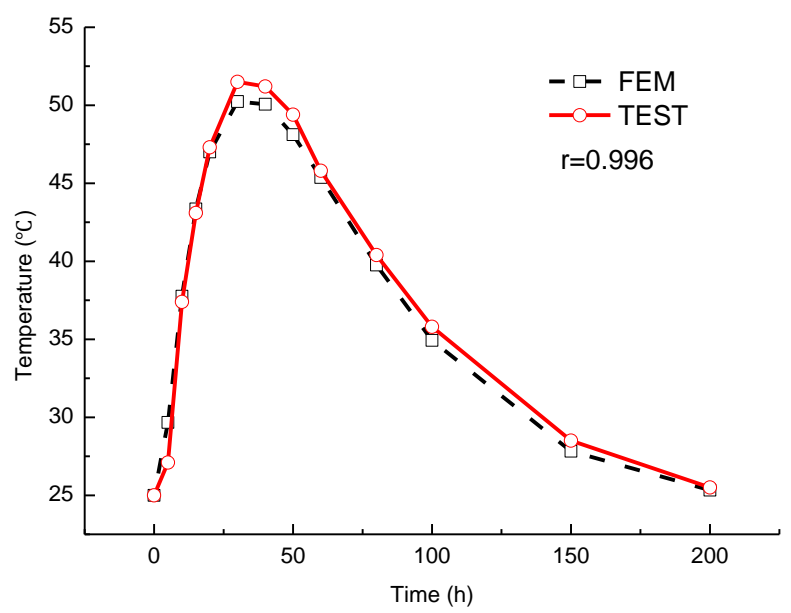

(b) Test point 3

Fig. 4 - Comparison between FEM and test values of temperature 


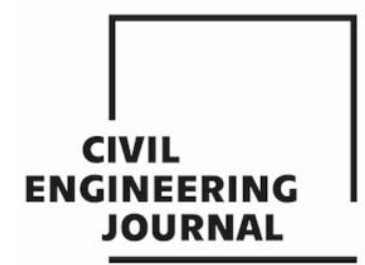

Article no. 39

THE CIVIL ENGINEERING JOURNAL 2-2021

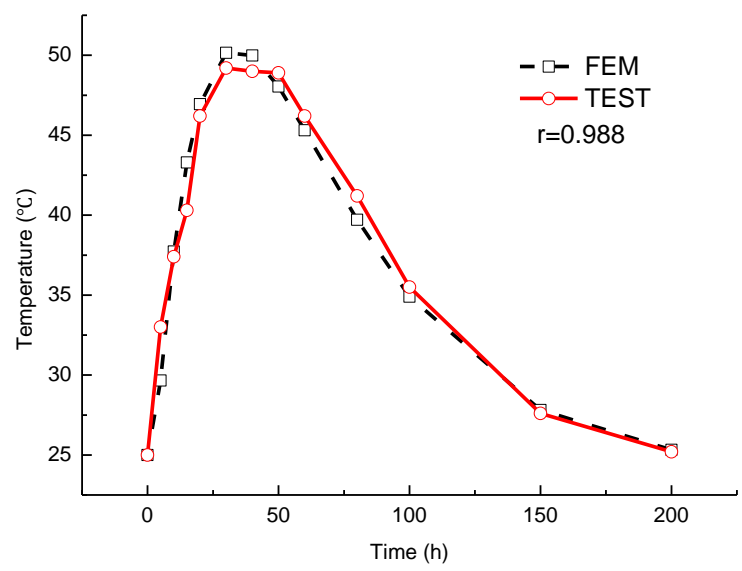

(c) Test point 8

Fig. 4 - Comparison between FEM and test values of temperature

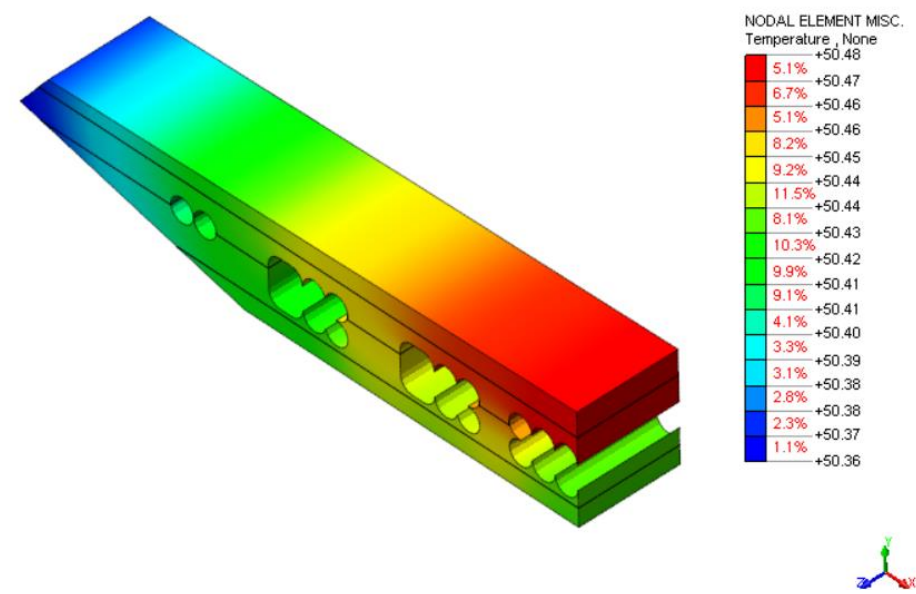

Fig. 5 - Temperature stress nephogram of box girder at $35 \mathrm{~h}$

It can be seen from Figure 4 that the measured temperature at the top of the roof at the central axis is significantly different from the calculated temperature at the temperature rise stage. In the concrete pouring, the superstructure of the set in steel pipe is poured in the later period, there is a time interval, and the hydration heat is late. Because of the large size of the test point on the upper part of the set in steel pipe, the measured temperature rise rate of hydration heat is faster than the calculated value, and the peak value of hydration heat is greater than the calculated value. The test point at the upper part of the central axis reaches the peak time later than the calculated value, because the lower part is first poured and then the upper part is poured, so there is a certain delay in time. The outbursts in the measured curves are caused by environmental factors and are measured at a time of day when the temperature is high. The cooling rate of the late is slower than the calculated value, which is determined by the position of the test points.

According to the comparison between Figure 4 (a) and Figure 4 (b), the duration of high temperature in the center of the roof at the axis is longer than in other parts of the roof. The measured data and calculated values at the center of the roof test point 3 fit well in the temperature rise stage. Figure 4 (c) shows the measured value curve of test point 8 at the center of the air nozzle fits well with the calculated value curve. In the temperature rising stage, the maximum error between measured and calculated values is about $3^{\circ} \mathrm{C}$. There are several abrupt changes of temperature in the time history curve of measured temperature value, which are obviously different from the calculated value. This is caused by the influence of external factors such as sunshine, air humidity 


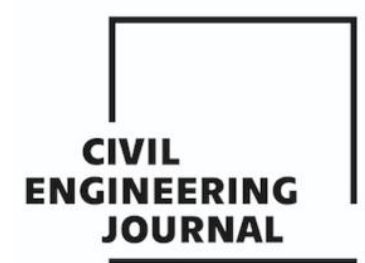

Article no. 39

THE CIVIL ENGINEERING JOURNAL 2-2021

and wind speed, which are not considered in the calculation. Considering comprehensively, the difference between the measured value and the calculated value is within the allowable range, and the model can be used for the next stage of parameter analysis.

\section{PARAMETER STUDY}

During the construction, the change of diameter, spacing and flow rate of cooling water pipes will lead to the change of temperature field in concrete. To reduce the hydration heat at the maximum efficiency and the capital cost at the same time, the relevant parameters of cooling water pipes are analyzed.

\section{Diameter of cooling water pipe}

The diameter of cooling water pipe decides the area of contact between cold water and concrete. To study the diameter of the cooling water pipe when the cooling effect is ideal under the condition of changing the diameter of the cooling water pipe, this paper calculates the temperature value of the test point when the diameter is $9 \mathrm{~mm}, 15 \mathrm{~mm}, 21 \mathrm{~mm}, 27 \mathrm{~mm}, 33 \mathrm{~mm}, 39 \mathrm{~mm}$ and $45 \mathrm{~mm}$ respectively. Figure 6 (a) shows the temperature change of test point 1 with different cooling water pipe diameters.

As seen in Figure $6(\mathrm{a})$, the temperature variation trend is the same under different cooling water pipe diameters. Concrete reaches its peak temperature about 35 hours after casting, and then the concrete temperature decreases rapidly at first and then slowly. When the diameter of cooling water pipe is $9 \mathrm{~mm}$, the maximum instantaneous temperature rise rate of test point is $1.662^{\circ} \mathrm{C} / \mathrm{h}$, and the maximum instantaneous temperature drop rate is $0.293^{\circ} \mathrm{C} / \mathrm{h}$. When the diameter of cooling water pipe is $21 \mathrm{~mm}$, the maximum instantaneous temperature rise rate of the test point is $1.616^{\circ} \mathrm{C} / \mathrm{h}$, and the maximum instantaneous temperature drop rate is $0.296^{\circ} \mathrm{C} / \mathrm{h}$. When the diameter of cooling water pipe is $33 \mathrm{~mm}$, the maximum instantaneous temperature rise rate of test point is $1.572^{\circ} \mathrm{C} / \mathrm{h}$, and the maximum instantaneous temperature drop rate is $0.294^{\circ} \mathrm{C} / \mathrm{h}$. When the diameter of cooling water pipe is $45 \mathrm{~mm}$, the maximum instantaneous temperature rise rate of the test point is $1.530^{\circ} \mathrm{C} / \mathrm{h}$, and the maximum instantaneous temperature drop rate is $0.290^{\circ} \mathrm{C} / \mathrm{h}$. According to the function fitted by the maximum instantaneous temperature drop rate, as shown in formula (7), the diameter of the water pipe is $25 \mathrm{~mm}$ when the maximum instantaneous temperature drop rate is achieved.

$$
y=e^{-5.867 \times 10^{-5} x^{2}+0.00281 x-1.248}
$$

\section{(2) Spacing of cooling water pipes}

The distance between cooling water pipes decides the influence of different water pipes on the same concrete. In this paper, the temperature values of test points are calculated when the horizontal spacing of water pipes is $0.5 \mathrm{~m}, 1.0 \mathrm{~m}$ and $1.5 \mathrm{~m}$ respectively. Figure 6 (b) shows the temperature change of test point 1 under different horizontal spacing of cooling water pipes.

According to Figure $6(\mathrm{~b})$, when the horizontal spacing of cooling water pipes is $0.5 \mathrm{~m}$, the maximum instantaneous temperature rise rate is $1.571^{\circ} \mathrm{C} / \mathrm{h}$, and the maximum instantaneous temperature drop rate is $0.294^{\circ} \mathrm{C} / \mathrm{h}$. When the horizontal distance between water pipes is $1.0 \mathrm{~m}$, the maximum instantaneous temperature rise rate is $1.620^{\circ} \mathrm{C} / \mathrm{h}$, and the maximum instantaneous temperature drop rate is $0.296^{\circ} \mathrm{C} / \mathrm{h}$. When the horizontal spacing of water pipes is $1.5 \mathrm{~m}$, the maximum instantaneous temperature rise rate is $1.637^{\circ} \mathrm{C} / \mathrm{h}$, and the maximum instantaneous temperature drop rate is $0.295^{\circ} \mathrm{C} / \mathrm{h}$. According to the fitting function of the maximum instantaneous temperature drop rate, as shown in formula (8), it can be known when the maximum instantaneous temperature drop rate is achieved, the horizontal spacing of water pipes is $1.0 \mathrm{~m}$.

$$
y=0.29467+0.0015 \sin \left(\pi \frac{x-0.625}{0.75}\right)
$$




\section{(3) Temperature of inlet water}

Temperature of inlet water is a factor that has a great influence on the cooling effect. This paper calculates the temperature values of test points when the water inlet temperature is $5^{\circ} \mathrm{C}, 10^{\circ} \mathrm{C}$, $15^{\circ} \mathrm{C}, 20^{\circ} \mathrm{C}$ and there is no cooling water pipe. Figure 6 (c) shows the temperature change of test point 1 at different water inlet temperatures.

As seen in Figure 6 (c), when there is no cooling water pipe, concrete reaches its peak temperature about 40 hours after casting. When cold water is injected, concrete reaches its peak temperature about 5 hours earlier, and the peak temperature decreases by more than $3^{\circ} \mathrm{C}$. When the water inlet temperature is $5^{\circ} \mathrm{C}$, the maximum instantaneous temperature rise rate is $1.538^{\circ} \mathrm{C} / \mathrm{h}$, and the maximum instantaneous temperature drop rate is $0.305^{\circ} \mathrm{C} / \mathrm{h}$. When the water inlet temperature is $15^{\circ} \mathrm{C}$, the maximum instantaneous temperature rise rate is $1.590^{\circ} \mathrm{C} / \mathrm{h}$, and the maximum instantaneous temperature drop rate is $0.299^{\circ} \mathrm{C} / \mathrm{h}$. When there is no cooling water pipe, the maximum instantaneous temperature rise rate is $1.698^{\circ} \mathrm{C} / \mathrm{h}$, and the maximum instantaneous temperature drop rate is $0.288^{\circ} \mathrm{C} / \mathrm{h}$. It can be seen from Fig.6 (c) the change of water inlet temperature has a significant influence on the temperature produced by hydration heat.

\section{(4) Flow rate of water}

In this paper, the temperature values of test points are calculated when the flow rate is $0.4 \mathrm{~m}^{3} / \mathrm{h}, 1.2 \mathrm{~m}^{3} / \mathrm{h}, 1.6 \mathrm{~m}^{3} / \mathrm{h}, 2.0 \mathrm{~m}^{3} / \mathrm{h}, 2.4 \mathrm{~m}^{3} / \mathrm{h}, 2.8 \mathrm{~m}^{3} / \mathrm{h}, 3.2 \mathrm{~m}^{3} / \mathrm{h}$. Figure $6(\mathrm{~d})$ shows the temperature change of test point 1 at different water flow rates.

According to Figure $6(\mathrm{~d})$, when the flow rate is $0.4 \mathrm{~m}^{3} / \mathrm{h}$, the maximum instantaneous temperature rise rate is $1.614^{\circ} \mathrm{C} / \mathrm{h}$, and the maximum instantaneous temperature drop rate is $0.296^{\circ} \mathrm{C} / \mathrm{h}$. When the flow rate is $1.6 \mathrm{~m}^{3} / \mathrm{h}$, the maximum instantaneous temperature rise rate is $1.614^{\circ} \mathrm{C} / \mathrm{h}$, and the maximum instantaneous temperature drop rate is $0.296^{\circ} \mathrm{C} / \mathrm{h}$. When the flow rate is $2.4 \mathrm{~m}^{3} / \mathrm{h}$, the maximum instantaneous temperature rise rate is $1.614^{\circ} \mathrm{C} / \mathrm{h}$, and the maximum instantaneous temperature drop rate is $0.296^{\circ} \mathrm{C} / \mathrm{h}$. When the flow rate is $3.2 \mathrm{~m}^{3} / \mathrm{h}$, the maximum instantaneous temperature rise rate is $1.614^{\circ} \mathrm{C} / \mathrm{h}$, and the maximum instantaneous temperature drop rate is $0.296^{\circ} \mathrm{C} / \mathrm{h}$. According to Figure 6 (d), the change of water flow rate has little influence on the temperature produced by hydration heat.

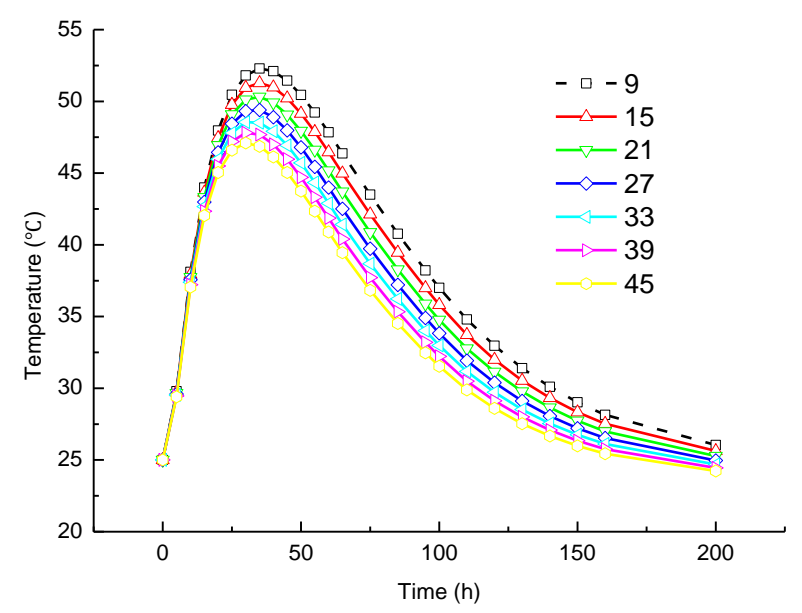

(a) Different diameters of cooling water pipes

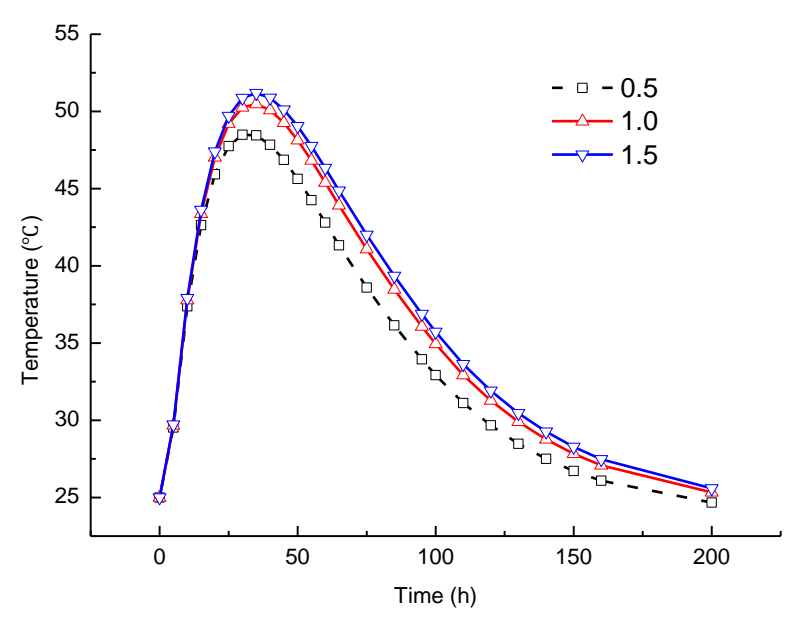

(b) Different spacing of cooling water pipes

Fig. 6 - Temperature changes of test point 1 under different parameters 


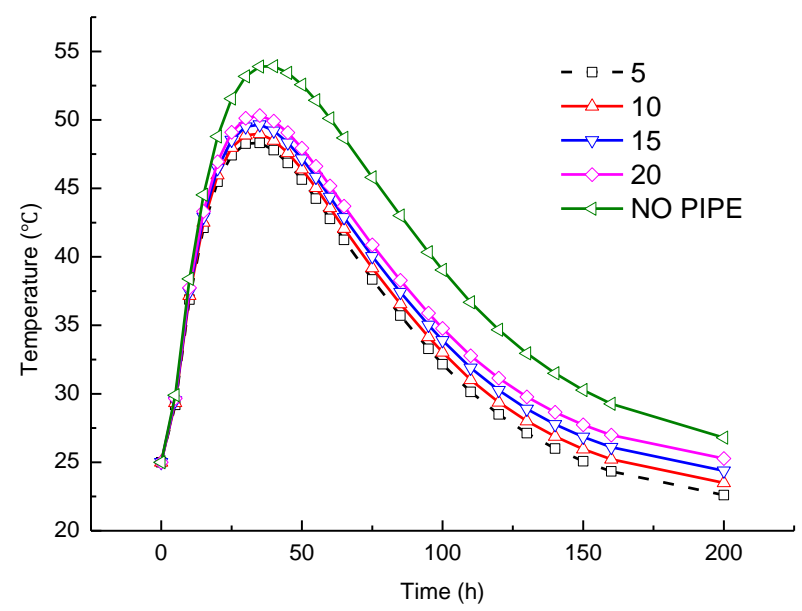

(c) Different temperatures of inlet water

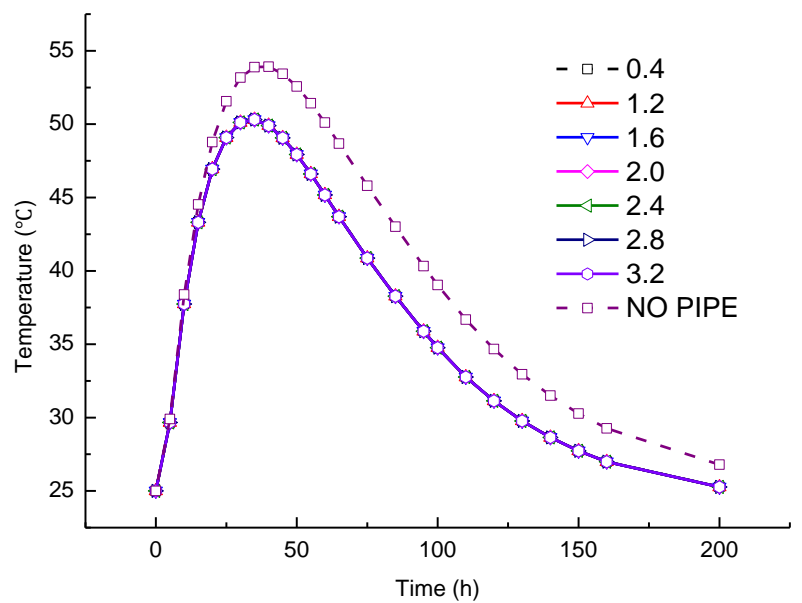

(d) Different flow rates of water

Fig. 6 - Temperature changes of test point 1 under different parameters

The influence of different parameters changes on the temperature of measurement point 1 are compared, as shown in Figure 7. As can be seen from the figure, the change of diameter of the water pipe and temperature of inlet water have a great influence on the Temperature, while water inlet rate has a small influence.

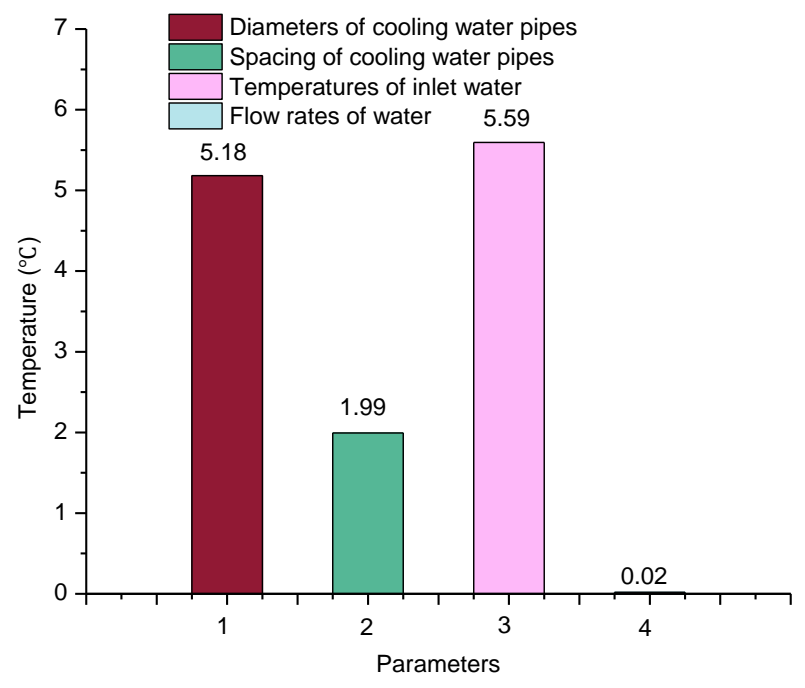

Fig. 7-Different parameters influence comparison

\section{CONCLUSION}

In this paper, the cooling water pipe layout and field measurement of the mass concrete in the joint section of box girder of a cable-stayed bridge are carried out, and the finite element software is used for simulation calculation. The influence of the change of relevant parameters of cooling water pipe on the temperature field of concrete is systematically analyzed. The research conclusions are as follows:

(1) Between 30 45h after concrete pouring, the temperature reaches the highest value, and the concrete temperature rises sharply first and drops slowly.

(2) The calculated value of finite element is in well agreement with the field measured data. 


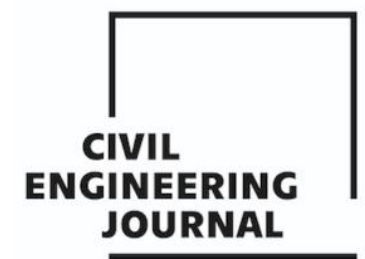

Article no. 39

THE CIVIL ENGINEERING JOURNAL 2-2021

(3) Among the parameters related to the cooling water pipe, the change of water inlet temperature and water pipe diameter has a greater impact on the concrete temperature, while the change of water inlet rate has a smaller impact on the temperature.

(4) When only the diameter of the water pipe is changed, the fitting function can be gained by considering the instantaneous temperature drop rate. Based on this, the ideal effect can be gained when the diameter of the water pipe is $25 \mathrm{~mm}$.

(5) When only the horizontal spacing of water pipes is changed, the fitting function can be gained by considering the instantaneous temperature drop rate. Based on this, the horizontal spacing of water pipes is $1.0 \mathrm{~m}$.

\section{ACKNOWLEDGEMENTS}

This paper is supported by the Anyang Science and Technology Plan Project (2020) (grant number: 251) and Anyang Institute of Technology Research and Cultivation Fund (grant number: YPY2020021).

\section{REFERENCES}

[1] Wang Xiushan, Hou Ning, 2019. Influence Research of Water Pipe Cooling on Temperature Stress of Mass Concrete (China Concrete and Cement Products), 15-18.

[2] Song Fuchun, Liu Ce, 2015. Analysis on Hydration Heat of Massive Concrete with Pipe Water Cooling (Journal of Shenyang Jianzhu University(Natural Science)) , 95-101.

[3] Zhang Yiduo, Guo Yiquan, Zhang Guoyun, 2015. Numerical Analysis on Hydration Heat Temperature Field of Prestressed Concrete Box Girder(China Concrete and Cement Products), 44-47.

[4] Zhu Bofang, 1999. Temperature stress and temperature control of mass concrete (Beijing: China Electric Power Press), 1-7 pp.

[5] Ding Baoying, 1997. Determination of temperature difference of water pipe between mass concrete and cooling water pipe(Water Resources and Hydropower Engineering), 12-16.

[6] Liu Yaodong, Bai Yinghua. et al., 2009. Optimization research on cooling pipe of mass concrete pier cap based on MIDAS(Concrete), 110-112.

[7] Sanyuan Guo, Caiping Huang, Henglin Xiao, 2016. Control and Optimization of After Rirer's Mass Concrete Pile Cap Cooling Tube(Highway Engineering),136-139.

[8] Tang Yang, Cao Haiyang, 2019. Effects of Layout Line of Cooling water pipes and Setting Parameters on Hydration Heat of the Caps(China Concrete and Cement Products), 86-91.

[9] Liu Guangting, Hu Yu, 2002. Analysis and measurement of the temperature field in the Shimenzi RCC arch dam[J]. (Journal of Tsinghua University(Science and Technology)), 539-542.

[10] Chen Zhijun, Kang Wenjing, Li Li, 2007. Study of the temperature effect caused by heat of hydration in hollow-thin pier (Journal of Huazhong University of Science and Technology(Natural Science Edition)) ,105108.

[11] Zhang Yongjian, Li Ou, 2016. Test Study of Temperature Control of Mass Concrete for Pile Caps of Dongting Lake Bridge (Bridge Construction), 45-50.

[12] Wang Jianqun, Wei Guiliang, 2020. Measurement and Analysis of Hydration Heat in Massive Concrete Pile Cap of a Sea-Crossing Bridge (Bridge Construction),25-31.

[13] Liu Yi, Chen Bing, 2010. Numerical Simulation of Hydrated Heat Temperature Field of Massive Concrete (China Concrete and Cement Products), 15-18+27.

[14] Liu Guoxing, Huang Yonghui, Wan Yang, 2018. Experimental Research and Numerical Simulation on Hydration Heat of Bridge Mass Concrete(China Concrete and Cement Products), 94-97. 